\title{
Palliative care training substandard
}

$\mathrm{M}$ ost of the hundreds of thousands of Canadians who die each year from natural causes spend their final days under the care of family doctors and nurses. Many experts in end-of-life care question whether these caregivers have the skills necessary to ensure dying patients meet peaceful ends, and are calling for more palliative experts and increased training for all physicians.

To that end, efforts have been initiated to create a subspecialty in palliative medicine, but experts say there's still a need for more core training of all physicians about its nuances.

"I think that palliative care is similar to, say, cardiology, where all physicians, all nurses and health care professionals need to have a base level of knowledge in order to manage most of the issues of patients," says Dr. Deborah Dudgeon, cochair of the Royal College of Physicians and Surgeons of Canada and the College of Family Physicians of Canada Conjoint Advisory Committee on Palliative Medicine. "But once things get a bit more complex, then there needs to be another one or two levels of expertise that can support people so that they can get optimal care."

Numerous studies have shown there are significant variations in the quality of palliative care that Canadians receive (www.cmaj.ca/lookup/doi/10.1503/cmaj .109-3763). The Canadian Hospice Palliative Care Association has found that access to palliative care was very much a matter of luck of the draw (www .chpca.net/resource_doc_library/HPC_ Policy_Brief_Systems_Approach_June _2010.pdf), while the Quality End-ofLife Care Coalition of Canada found that "the gap between what Canadians want at the end of life and what they experience has been due, in part, to the variability in the hospice palliative care services provided at home in different jurisdictions" (www.chpca.net/qelccc /hphc-progress_report/Hospice_Palliative _Home_Care_Progress_Report-final.pdf).

Retired Liberal senator Sharon

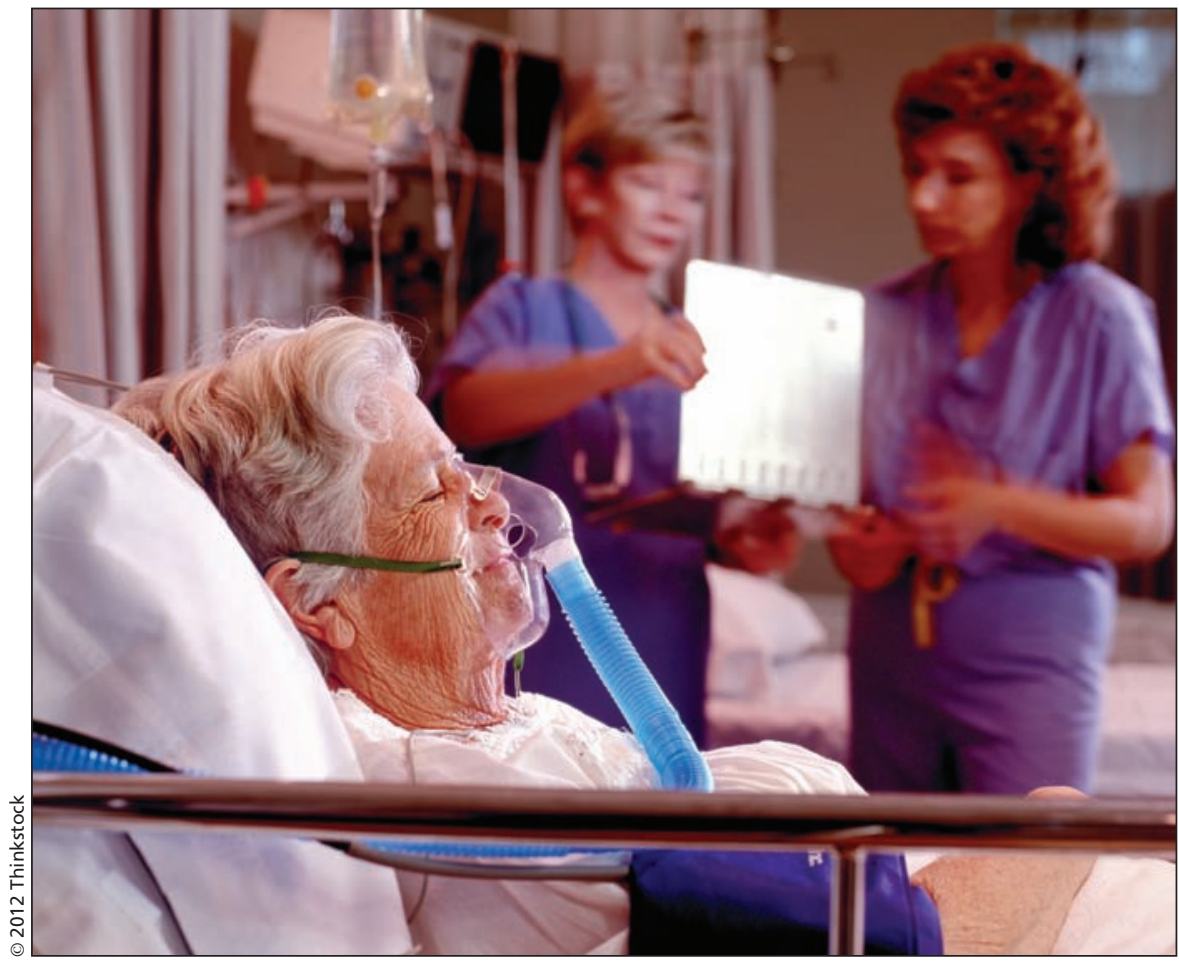

Research suggests people would prefer to die at home while receiving appropriate endof-life care, but most Canadians still die in primary care without assistance from palliative care experts.

Carstairs, a long-time crusader for improved end-of-life care, noted in a report, Raising the Bar: A Roadmap for the Future of Palliative Care in Canada, that "there are still Canadians dying in needless pain because health care providers do not know what a good death is" (www.virtualhospice.ca/Assets /Raising\%20the\%20Bar\%20June\%202 010_Senator\%20Sharon\%20Carstairs _20100608160433.pdf).

Although studies repeatedly show that most people would prefer to die at home while receiving appropriate endof-life care, that's generally not the norm.

"The bottom line is $65 \%$ of all Canadians die in primary care," says Sharon Baxter, executive director of the Canadian Hospice Palliative Care Association. "They don't have a palliative care physician or social worker engaged."

The aging of Canada's population will make the need for better trained health care providers that much more critical in the future, the association says (www.chpca.net/media/7622/fact _sheet_hpc_in_canada_may_2012_final .pdf). Others, including the Canadian Geriatric Society, have argued that the need is so compelling that the provision of geriatric training for undergraduate medical students should be a condition of accreditation of medical schools, as well as a competency tested on licensing exams (www.cmaj.ca/lookup/doi /10.1503/cmaj.109-4195).

Demand for palliative care is rising because there are more elderly patients with chronic conditions and more illnesses that require such treatment, experts say. "We've been traditionally focused on patients with cancer," says Dr. Cori Schroder, cochair of the Royal College of Physicians and Surgeons of Canada and the College of Family Physicians of Canada Conjoint Advisory Committee on Palliative Medicine. "We now are looking after people with con- 
gestive heart failure, with respiratory difficulties, with ALS [amyotrophic lateral sclerosis], people who are on dialysis."

Some steps have been taken to bolster the ranks of experts and increase the baseline knowledge of all health care providers. Although defunct, the Educating Future Physicians in Palliative and End-of-Life Care (EFPPEC) program developed six core competencies: management of pain and symptoms, such as through evidence-based opioid strategies; response to psychosocial and spiritual needs; assistance in end-of-life decision-making and planning; effective communication with patients and families; interdisciplinary collaboration; and easing the suffering of terminally ill patients (www.afmc.ca/efppec/docs /pdf_2008_efppec_core_competencies _en.pdf). As a result of the program, those competencies must be integrated in some form into the curricula of Canadian undergraduate medical schools, though no specifics are prescribed on how that content is expressed.

Translation of those competencies into curricula has been checkerboard, Schroder writes in an email. "Since EFPPEC, there has been some improvement in the knowledge, skills and attitudes of graduating medical students regarding palliative and end-of-life care but it is still less than adequate as the 'translation' into curriculum is variable across Canada."

More research would be needed to determine how effectively the competencies are being reflected in medical school curricula, says Dr. Larry Librach, Sun Life Financial chair in bioethics and director of the Joint Centre for Bioethics at the University of Toronto in Ontario and past director of the Temmy Latner Centre for Palliative Care at Mount Sinai Hospital in Toronto. Palliative care education in postgraduate medical schools remains sparse, he says. "We'd like to think that the enhanced curriculum does produce better physicians, but the postgraduate side of things needs to complement what they're seeing in the undergraduate and doing in the undergraduate."

For existing health care practitioners looking to acquire advanced skills, various Canadian medical schools offer a one-year program of added competence in palliative medicine for medical graduates jointly accredited by the Royal College of Physicians and Surgeons of Canada and the College of Family Physicians of Canada. Nurses can opt for certification in palliative care through the Canadian Nurses Association.

Recognizing palliative medicine as a subspecialty would doubtlessly have a major impact on bolstering training in the field, says Dudgeon. To that end, the Royal College of Physicians and Surgeons of Canada is considering a two-year subspecialty in palliative medicine. The Royal College's Committee on Specialties approved the notion and it's hoped it will be finalized within a year, Dudgeon adds. As well, the College of Family Physicians of Canada is developing the criteria for a one-year certification program in palliative medicine.

Subspecialization in palliative medicine would offer several benefits, Schroder says. Specialists would be more readily able to treat complex cases, contribute to research on palliative medicine and help train the next generation of physicians in palliative care.

But ensuring that all physicians nationwide are adequately trained in palliative care will require "some push from above" (i.e., government policies and resources), as well as public demand for quality end-of-life care, says Librach. "It's really going to require a top-down approach and it's going to require institutions that say quality end-of-life care is as important to us as quality birthing care or quality of care in the emergency department." - Michael Monette, CMAJ

CMAJ 2012. DOI:10.1503/cmaj.109-4223 